\title{
The renal resistive index as a predictor of acute hydronephrosis in patients with renal colic
}

\author{
E.M.S. Piazzese ${ }^{a, *}$, G.I. Mazzeo ${ }^{a}$, S. Galipò ${ }^{a}$, F. Fiumara ${ }^{\text {b }}$, C. Canfora ${ }^{c}$, \\ L.G. Angiò ${ }^{d}$
}

${ }^{a}$ General Surgery Unit, San Camillo Clinic, Messina, Italy

${ }^{\mathrm{b}}$ Emergency Department, Humanitas-Gavazzeni Hospital, Bergamo, Italy

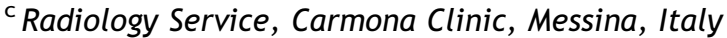

d School of Specialization in General Surgery I, University of Messina, Messina, Italy

\section{KEYWORDS \\ Renal colic; \\ Hydronephrosis; \\ Renal color Doppler \\ ultrasound; \\ Renal resistive index.}

\begin{abstract}
Introduction: The objective of this study was to determine whether the renal resistive index (RI) can predict hydronephrosis in patients with renal colic (RC) and whether or not its performance is time-dependent.

Materials and methods: The study population was composed of 54 patients admitted for unilateral RC. At the time of the first observation (time point I, tpl), each patient underwent routine examinations, abdominal ultrasonography, and renal color Doppler ultrasound (CDUS) with measurement of the RI. The two imaging studies were repeated $6,12,18,24$, 36, and $48 \mathrm{~h}$ later (tpII, tpIII, tpIV, tpV, tpVI, tpVII). In addition, each patient underwent noncontrast urinary tract CT $48-60 \mathrm{~h}$ after admission. A mean renal $\mathrm{RI}$ of $>0.70(\mathrm{mRI}+)$ for the symptomatic kidney was considered indicative of obstruction. Patients were retrospectively divided into two groups: those who developed dilatation (group A) and those who did not (group B).

Results: A mRI+ on CDUS predicted the onset of hydronephrosis with $100 \%$ sensitivity, $84 \%$ specificity, $92.6 \%$ accuracy, PPV and NPV of $87.9 \%$ and $100 \%$, and diagnostic efficiency of $84 \%$. In group A, mRI+ were always observed before onset of hydronephrosis in a timedependent manner. In group B, mRI+ were observed occasionally in 4/25 patients (16\%) and all were recorded at tpll. In these cases, the RI had returned to normal by tpllI. Conclusions: In our RC patients, renal RI obtained with CDUS predicted the onset of acute dilatation with higher sensitivity, specificity, accuracy, and diagnostic efficiency than ultrasonography, and it can be used routinely in the emergency department to supplement ultrasound findings.
\end{abstract}

\footnotetext{
* Corresponding author. Clinica San Camillo, Viale Principe Umberto n.71, 98122 Messina, Italy.

E-mail address: enricopiazzese@hotmail.com (E.M.S. Piazzese).
} 
Sommario Introduzione: Obiettivo di questo studio è stato verificare se l'Indice di Resistenza Renale (IR) possa essere considerato un parametro predittivo dell'insorgenza dell'idronefrosi (IN) in caso di colica renale (CR) monolaterale e se esso è tempo correlato.

Materiali e metodi: Lo studio ha incluso 54 pazienti ricoverati per CR monolaterale. Al momento della prima osservazione (time point I) tutti i pazienti sono stati sottoposti a esami routinari, a Ecografia addome e a Eco color Doppler renale (ECD) bilaterale con misurazione dell'IR. Dopo 6 (tpll), 12 (tpIII), 18 (tpIV), 24 (tpV), 36 (tpVI) e 48 (tpVII) ore è stata ripetuta l'ecografia dell'apparato urinario e l'ECD con la misurazione bilaterale dell'IR. A 48-60 ore dal ricovero inoltre tutti i pazienti sono stati sottoposti a TC dell'apparato urinario senza mezzo di contrasto. Un valore medio di IR maggiore di 0,70 (mRI+) a livello del rene sintomatico è stato considerato come suggestivo di ostruzione. I pazienti, in relazione allo sviluppo di IN, sono stati suddivisi a posteriori in gruppo A (dilatazione presente) e B (dilatazione assente). Risultati: L'ECD con il rilevamento dei valori $\mathrm{mRI}+$ ha mostrato un significativo valore diagnostico relativamente all'insorgenza dell'IN con una sensibilità del $100 \%$, specificità $84 \%$, accuratezza $92,6 \%$, VPP $87,9 \%$, VPN $100 \%$ ed efficienza diagnostica $84 \%$. Inoltre, nel gruppo A, i valori $\mathrm{mRI}+$ sono stati registrati sempre precocemente rispetto all'insorgenza dell'idronefrosi e in modo tempo correlato. Anche nel gruppo B sono stati registrati alcuni mRI+, ma solo in 4/ 25 pazienti (16\%) e tutti al time point II; in questi casi comunque $i$ valori di mIR sono rientrati nei range della normalità già nel time point successivo.

Conclusioni: Nel nostro studio l'ECD con la misurazione dell'IR si è dimostrato capace di diagnosticare anticipatamente l'insorgenza della dilatazione acuta con livelli di sensibilità, specificità, accuratezza ed efficienza diagnostica superiori all'ecografia; si può prospettare quindi il suo impiego routinario nei reparti di emergenza ad integrazione dell'ecografia.

(c) 2012 Elsevier Srl. All rights reserved.

\section{Introduction}

Renal colic $(\mathrm{RC})$ is one of the most common conditions seen in the emergency department (ED). The frequency of $\mathrm{RC}$ in the general population ranges from $2 \%$ to $12 \%$, and it accounts for $30-35 \%$ of all urological emergencies. The incidence is higher in men (10-20\% vs $3-5 \%$ in women), and $30-40 \%$ of all patients experience symptomatic recurrence within 5 years [1-3]. In most cases, the colic is caused by ureteral spasm in response to the passage of a calculus, but in rare cases the pain stems from the transit of a blood clot (secondary to trauma or neoplastic disease), fibrin (caused by infection), tissue fragments (urinary tract tumors or acute renal necrosis), or other factors [4,5].

Regardless of the cause, patients with RC are at risk for acute urinary obstruction (partial or complete) leading to hydronephrosis. The frequency of this complication ranges from $33 \%$ to $68.3 \%$ [6-9]. Hydronephrosis is a serious clinical problem because it can produce progressive deterioration of renal function over time [10]. If the obstruction is caused by urolithiasis, spontaneous resolution can occur, more or less rapidly. The frequency of this outcome depends on the size of the stone. If the latter is less than $2 \mathrm{~mm}$ in diameter, all cases generally resolve spontaneously within 4 weeks; the frequency drops to $80 \%$ for calculi 2-4 $\mathrm{mm}$, to $50 \%$ for those $4-6 \mathrm{~mm}$, and to $10 \%$ for those larger than $6 \mathrm{~mm}$. If the calculus has not been expelled after 4-5 weeks, renal function impairment can become severe and sometime irreversible [11]. For this reason, the obstruction needs to be diagnosed and treated as soon as possible. Some studies have shown that dilatation may be absent in the early phases of renal colic, especially in dehydrated patients ( $30 \%$ of all cases), and this can lead to misdiagnosis [12].

The imaging studies most frequently ordered in the ED for patients with renal colic are plain abdominal radiography and ultrasonography; urography, CT, and MRI are considered second-line studies. The advantages, limitations, and sensitivity/specificity of each of these methods in identifying the cause, site, and degree of obstruction have been well documented in the literature. Plain films alone of the urinary tract are of limited value in identifying ureteral calculi (sensitivity 53-62\%, specificity $67-69 \%)[13,14]$. Urography has a sensitivity of $87 \%$ and specificity of $94 \%[15,16]$, but most authors do not feel that it is useful in the acute phase of RC, particularly in view of the risks it entails and its contraindications (renal failure, dehydration, allergy to contrast material, pregnancy). For this reason, they prefer to use urography more selectively as a second-level study for cases that cannot be diagnosed with other means [17]. CT without contrast enhancement has excellent sensitivity (91-100\%) and specificity $(91-97 \%)[18,19]$, and it is undoubtedly the examination of choice when RC is suspected because it reduces assessment times and allows the physician to identify other causes of the patient's pain [20,21]. In fact, in $57 \%$ of the patients whose CTs are negative for urinary calculi, other lesions are discovered (aneurysms of the abdominal aorta, appendicitis, diverticulitis, bladder tumors). A major drawback to the use of CT is the radiation exposure it causes, which makes it unsuitable for monitoring purposes $[22,23]$. In addition, calculi that are not radiopaque and those smaller than $3 \mathrm{~mm}$ are difficult to 
detect and to differentiate from other hyperdense images, such as phleboliths or vascular calcifications [24]. MRI displays good diagnostic accuracy in identifying urinary tract dilatation (sensitivity $100 \%$, specificity $96 \%$ ) and the cause of the obstruction (in $88-92 \%$ of all patients). It can also be used to distinguish between acute and chronic ureteral obstruction (on the basis of the perirenal signal) $[25,26]$. However, because of its cost and its limited availability, MRI is still not routinely used in EDs.

As for ultrasonography, this method has displayed high sensitivity and specificity for detection of urinary tract obstruction. Sensitivity ranges from $91 \%$ to $92 \%$ (94-97\% when it is combined with plain films of the urinary apparatus), and sensitivity is around $90 \%$. However, its advantages (repeatability and absence of exposure to radiation or iodinated contrast agents, which makes it safe-even in pregnant women) must be weighed against its limitations: operator-dependency, results that are influenced by patient hydration, and variable rates of success in identifying ureteral calculi (4-38\%), especially in patients who are obese or uncooperative and those with large amounts of intestinal gas $[8,9,27]$.

The results of recent studies suggest that patients with RC should be evaluated with color Doppler imaging of the kidneys instead of gray-scale sonography alone. These studies showed that the renal resistive index $(\mathrm{RI})$, one of the variables assessed with this method, is elevated in the presence of hydronephrosis, and the index also displays clear correlation with the degree and duration of the urinary tract obstruction $[7,10,28,29]$.

The objectives of the present prospective study were to determine whether, in patients with unilateral RC, the RI can predict the onset of hydronephrosis and if so, whether its predictive value is time-dependent.

\section{Materials and methods}

The study population comprised 54 patients admitted to the ED with unilateral RC. Inclusion criteria were: 1) patient history, clinical findings, and laboratory data all negative for medical nephropathy, obstructive uropathy, cardiovascular disease, and metabolic disease; 2) age 20-50 years; 3) no drugs administered before the first observation; 4) symptom onset less than $4 \mathrm{~h}$ before enrolment.

At the time of the first observation (time point [tpl]) all patients had: 1) blood drawn for laboratory studies; 2) an ECG and cardiologic examination; 3) plain film of the urinary tract; 4) abdominal US; 5) bilateral color Doppler ultrasound (CDUS) with measurement of the renal RIs. All patients were treated according to the same protocol, which provided for intramuscular injections of ketoprofen $100 \mathrm{mg}$ every $12-24 \mathrm{~h}$, intravenous hydration (2000 $\mathrm{ml}$ over $24 \mathrm{~h}$ at a constant rate of $83 \mathrm{ml} / \mathrm{h}$ ), and ciprofloxacin $500 \mathrm{mg}$ p.o.).

Six (tpl), 12 (tpllI), 18 (tplV), 24 (tpV), 36 (tpVI), and 48 (tpVII) hours after the first observation, urinary tract sonography and CDUS with bilateral measurement of the RI were repeated. The RI was expressed as follows: (peak systolic velocity - end diastolic velocity)/peak systolic velocity. Forty-eight to sixty hours after admission, all patients underwent CT of the urinary tract without contrast enhancement (the reference method). Each patient was examined sonographically by the same examiner. Examinations were done with the patient in the supine and lateral decubitus positions using the same machine (Philips EnVisor $\mathrm{HD}$ ) and a convex transducer (3.5-5 MHz). CDUS measurement of the RI (excluding aliasing phenomena and other artifacts) was carried out in the upper, middle, and lower portion of each kidney, between the interlobar arteries and the arcuate arteries. If the mean of the three measurements in the symptomatic kidney was greater than 0.70 , the test was regarded as indicative of obstruction. This finding is referred to hereafter as mean RI positivity $(\mathrm{mRI}+)$.

Based on data collected at the various time-points in the study, the patients were divided into two groups: those who presented signs of dilatation (group A) and those who did not (group B). The data were subjected to statistical analysis to identify: 1) possible differences between groups $A$ and $B$; 2 ) the relation between $\mathrm{mRI}+$ and the time of onset of hydronephrosis; 3 ) possible correlation between the $\mathrm{mRI}+$ and the level, degree, and duration of ureteral obstruction; 4) the sensitivity, specificity, positive and negative predictive values, accuracy, and efficiency of the method.

\section{Results}

The demographic and clinical features of the 54 patients investigated in this study are shown in Tables 1 and 2 . Tables 3 and 4 show, respectively, the number of $\mathrm{mRI}+$ recorded and the number of cases of hydronephrosis observed in the two groups (A and $B$ ) at each time point. There were no statistically significant differences between groups $A$ and $B$ in terms of demographic or clinical features. In $51 / 54$ cases ( $94.4 \%$ of the patients), the RC was attributed to ureteral calculosis on the basis of CT findings; in the other 3 cases, no cause was identified.

In the diagnosis of hydronephrosis, ultrasonography displayed excellent sensitivity, specificity, accuracy, PPV, and

Table 1 Demographic and clinical features of the study population.

\begin{tabular}{|c|c|c|}
\hline \multicolumn{3}{|c|}{ Demographic features } \\
\hline \multirow[t]{2}{*}{ Sex } & Males $35(64.8 \%)$ & \multirow[t]{2}{*}{$M / F=1.8: 1$} \\
\hline & Females 19 (35.2\%) & \\
\hline Age & Mean: 36.6 years & Range $22-50$ years \\
\hline \multicolumn{3}{|c|}{ Clinical features } \\
\hline \multirow[t]{7}{*}{ Symptoms } & Pain & $\begin{array}{l}\text { Right flank } 23 / 54 \\
(42.6 \%)\end{array}$ \\
\hline & & $\begin{array}{l}\text { Left flank } 31 / 54 \\
(57.4 \%)\end{array}$ \\
\hline & & $\begin{array}{l}\text { Duration } 4-38 \mathrm{~h} \\
\text { (mean } 7.2 \text { ) }\end{array}$ \\
\hline & Nausea - vomiting & $37 / 54(68.5 \%)$ \\
\hline & Dysuria & $41 / 54(75.9 \%)$ \\
\hline & Gross hematuria & $18 / 54(33.3 \%)$ \\
\hline & Fever & $11 / 54(20.4 \%)$ \\
\hline
\end{tabular}


Table 2 Results of diagnostic procedures performed in the study patients.

\begin{tabular}{|c|c|c|}
\hline \multicolumn{3}{|l|}{ Laboratory analyses } \\
\hline Leukocytosis & \multicolumn{2}{|l|}{$43 / 54(79.6 \%)$} \\
\hline Microhematuria & \multicolumn{2}{|l|}{$51 / 54$ (94.4\%) } \\
\hline Bacteriuria & \multicolumn{2}{|l|}{$14 / 54(25.9 \%)$} \\
\hline Crystalluria & \multicolumn{2}{|l|}{$33 / 54(61.1 \%)$} \\
\hline \multicolumn{3}{|l|}{$\begin{array}{l}\text { Plain radiography } \\
\text { of the urinary tract }\end{array}$} \\
\hline \multirow{3}{*}{$\begin{array}{l}\text { Radiopaque images } \\
\text { consistent with the } \\
\text { presence of calculi }\end{array}$} & $\begin{array}{l}\text { Presumed location: } \\
\text { kidney }\end{array}$ & $35 / 54(64.8 \%)$ \\
\hline & $\begin{array}{l}\text { Presumed location: } \\
\text { ureter }\end{array}$ & $37 / 54(68.5 \%)$ \\
\hline & $\begin{array}{l}\text { Presumed location: } \\
\text { bladder }\end{array}$ & $1 / 54(1.85 \%)$ \\
\hline \multicolumn{3}{|l|}{ Ultrasonography } \\
\hline \multirow[t]{4}{*}{ Calculosis } & Kidney & $47 / 54$ (87\%) \\
\hline & Proximal ureter & $17 / 54(27.8 \%)$ \\
\hline & Mid-distal ureter & $13 / 54(16.7 \%)$ \\
\hline & Bladder & $3 / 54$ (5.5\%) \\
\hline \multirow[t]{5}{*}{ Hydronephrosis } & Unilateral & $29 / 54(53.7 \%)$ \\
\hline & Bilateral & $0 / 54(0 \%)$ \\
\hline & Grade I & $5 / 29(17.2 \%)$ \\
\hline & Grade II & $8 / 29(27.6 \%)$ \\
\hline & Grade III & $16 / 29(55.2 \%)$ \\
\hline \multicolumn{3}{|l|}{$C T$} \\
\hline \multirow[t]{4}{*}{ Calculosis } & Kidney & $47 / 54(87 \%)$ \\
\hline & Proximal ureter & $31 / 54(57.4 \%)$ \\
\hline & Mid-distal ureter & $20 / 54(37 \%)$ \\
\hline & Bladder & $2 / 54$ (3.7\%) \\
\hline \multirow[t]{5}{*}{ Hydronephrosis } & Unilateral & $29 / 54(63.7 \%)$ \\
\hline & Bilateral & $0 / 54(0 \%)$ \\
\hline & Grade I & $4 / 29(13.8 \%)$ \\
\hline & Grade II & $11 / 29(37.9 \%)$ \\
\hline & Grade III & $14 / 29(48.3 \%)$ \\
\hline
\end{tabular}

Table 4 Number of cases of hydronephrosis observed at different time-points.

\begin{tabular}{llc}
\hline Time point & No. cases hydronephrosis (\%) \\
\hline tpl (admission) & 0 & 0 \\
tpll (6 h after admission) & 0 & 0 \\
tplll (12 h after admission) & $3 / 54$ & 5.5 \\
tplV (18 h after admission) & $14 / 54$ & 25.9 \\
tpV (24 h after admission) & $10 / 54$ & 18.5 \\
tpVI (36 h after admission) & $2 / 54$ & 3.7 \\
tpVII (48 h after admission) & 0 & 0 \\
Total & $29 / 54$ & $53.7 \%$ \\
\hline
\end{tabular}

NPV (all 100\%), but its performance declined in the identification of obstructing and nonobstructing calculosis in the two groups (sensitivity $72.4 \%$, specificity $64 \%$, accuracy $68.5 \%$, PPV 70\%, and NPV 66.7\%) (Table 5).

CDUS with calculation of the mRI+ was of substantial value in diagnosing the onset of hydronephrosis (sensitivity $100 \%$, specificity $84 \%$, accuracy $92.6 \%$, PPV $87.9 \%$, NPV $100 \%$, and efficiency $84 \%$ ) (Table 5 ). In group $\mathrm{A}, \mathrm{mRI}+$ was always observed before the onset of hydronephrosis $(100 \%$ of the cases) in an apparently time-dependent manner (an example is shown in Fig. 1); in particular, the interval between $\mathrm{mRI}+$ and detection of hydronephrosis was $6 \mathrm{~h}$ in $19 / 29$ cases $(65.5 \%), 12 \mathrm{~h}$ in $8 / 29$ cases $(27.6 \%)$, and $18 \mathrm{~h}$ in $2 / 29$ cases $(6.9 \%)$. Positive mRls were also observed in $4 / 25$ (16\%) patients in group $B$, and all were recorded at tpll. (An example is provided in Fig. 2.) In all four patients, the mRI observed at the next tp was already within the normal range.

No significant correlation was found between $\mathrm{mRI}$ values and the level of ureteral obstruction, the degree of

Table 3 Number of $\mathrm{mRI}+$ observed in groups $\mathrm{A}$ and B at the different time-points in the study.

\begin{tabular}{|c|c|c|c|}
\hline \multirow[t]{2}{*}{ Time point (tp) } & \multicolumn{2}{|l|}{ Group A } & \multirow{2}{*}{$\frac{\text { Group B }}{\text { No. cases (\%) }}$} \\
\hline & No. cases (\%) & $\begin{array}{l}\text { No. cases - hours before onset of } \\
\text { hydronephrosis }\end{array}$ & \\
\hline tpl (admission) & 0 & 0 & 0 \\
\hline tpll (6 $\mathrm{h}$ after admission) & $7 / 29(24.1 \%)$ & $\begin{array}{l}1 \text { case }-18 h \\
3 \text { cases }-12 h \\
3 \text { cases }-6 h\end{array}$ & $4 / 25(16 \%)$ \\
\hline tpIII (12 h after admission) & $16 / 29(55.1 \%)$ & $\begin{array}{l}5 \text { cases }-12 h \\
11 \text { cases }-6 h\end{array}$ & 0 \\
\hline tpIV (18 $\mathrm{h}$ after admission) & $5 / 29(17.2 \%)$ & $\begin{array}{l}1 \text { case }-18 \mathrm{~h} \\
4 \text { cases }-6 \mathrm{~h}\end{array}$ & 0 \\
\hline tpV (24 h after admission) & $1 / 29(3.4 \%)$ & 1 case $-6 h$ & 0 \\
\hline tpVI (36 $\mathrm{h}$ after admission) & 0 & 0 & 0 \\
\hline tpVII (48 $\mathrm{h}$ after admission) & 0 & 0 & 0 \\
\hline Total & $29 / 29(100 \%)$ & $\begin{array}{l}2 / 29 \text { cases }-18 \text { h }(6.9 \%) \\
8 / 29 \text { cases }-12 \text { h }(27.6 \%) \\
19 / 29 \text { cases }-6 \text { h }(65.5 \%)\end{array}$ & $4 / 25(16 \%)$ \\
\hline
\end{tabular}


Table 5 Sensitivity, specificity, accuracy, PPV, NPV, and efficiency of ultrasonography in the diagnosis of hydronephrosis and calculosis and of CDUS in predicting onset of hydronephrosis.

\begin{tabular}{lllll}
\hline & \multicolumn{2}{l}{ Ultrasonography } & & RI at CDUS \\
\cline { 2 - 3 } $\begin{array}{llll}\text { Diagnosis of } \\
\text { hydronephrosis }\end{array}$ & $\begin{array}{l}\text { Diagnosis of } \\
\text { ureteral } \\
\text { calculosis }\end{array}$ & & $\begin{array}{l}\text { Prediction } \\
\text { of onset of } \\
\text { hydronephrosis }\end{array}$ \\
\hline Sensitivity & $100 \%$ & $72.4 \%$ & $100 \%$ \\
Specificity & $100 \%$ & $64 \%$ & $84 \%$ \\
Accuracy & $100 \%$ & $68.5 \%$ & $92.6 \%$ \\
PPV & $100 \%$ & $70 \%$ & $87.9 \%$ \\
NPV & $100 \%$ & $66.7 \%$ & $100 \%$ \\
Efficiency & $100 \%$ & $36.4 \%$ & $84 \%$ \\
\hline
\end{tabular}

dilatation, the size of the obstructing calculus $(\leq 6 \mathrm{~mm}$ in 11 cases, $>6 \mathrm{~mm}$ in 18), or the duration of the pain (range 4-38 h).

In all of the patients in group A, the RI promptly returned to normal once the obstruction had resolved. Resolution occurred spontaneously in $[12 / 29(41.4 \%)]$ cases; in the other cases it was achieved with extracorporeal lithotripsy $(10 / 29,34.5 \%)$; removal of the stone with the aid of a Dormia basket (1 case, 3.4\%).

\section{Discussion}

There are numerous reports in the literature showing that CDUS with measurement of the RI is useful in the diagnosis of acute urinary tract obstruction in patients with recent onset $(6-48 \mathrm{~h})$ unilateral RC [7,29-31]. The RI is easy to calculate; it can even be provided automatically by the scanner itself. It represents an indirect estimate of the resistance present in the intrarenal vessels [32]. An acute urinary tract obstruction can increase the RI because this parameter is directly correlated with the pressure within the collection system. Indeed, dilation of the excretory ducts causes progressive compression of the renal parenchyma and renal vessels, and resistance within these vessels increases [30,32].

Early clinical studies produced contradictory results regarding the value of the supplementary information furnished by CDUS (compared with gray-scale ultrasound alone) and by measurement of the RI itself in the diagnosis of acute urinary tract obstruction [30,33].

In the 1980s Platt [30] and Sauvain [33] reported that RIs $>0.70$ were indicative of acute ureteral obstruction; since then, numerous studies conducted in animals and humans have confirmed this finding and attributed more or less high sensitivity and specificity to CDUS measurement of the RI [7,28,29,31,32].

In our study, the RI was found to predict the onset of acute dilatation with higher sensitivity, specificity, accuracy, and diagnostic efficiency than gray-scale US. In view of these findings and the temporal advantage it offers, we feel that the RI could be a useful prognostic marker for planning and monitoring responses to treatment for acute urinary tract obstruction. If an RI of $>0.70$ is indicative of obstruction with increased intrarenal pressures, patients with indexes in this range need prompt urinary tract decompression (via medical therapy, extracorporeal lithotripsy, endourologic procedures) to prevent irreversible damage, as confirmed by the more or less rapid $\mathrm{RI}$ normalization seen in our cohort and others once the obstruction has been eliminated [30,32,33].

Despite the encouraging results that emerged from our study and others, it is important to recall that this method has certain limitations. Above all, the RI has been shown to be influenced by a number of factors, including the patient's age, plasma renin levels, and the concomitant presence of diabetes, hypertension, heart disease, and many renal disorders. These factors can cause the RI to rise even in the absence of renal obstruction [10]. The population we studied was selected to minimize the effects of these variables. It was characterized by a well-defined age range and the absence of metabolic, cardiologic, renal, and urological disease.

It is also important to stress that the sensitivity and specificity of the RI varies in cases of partial obstruction. Data in the scientific literature confirm that this marker is more sensitive in the diagnosis of complete rather than partial obstructions [31,34,35]. de Toledo et al. [36], for example, reported a sensitivity of $91.8 \%$ in patients with complete obstruction but only $48.1 \%$ in those with partial obstruction. In the latter case, the intraureteral pressure is not high enough to increase intrarenal vascular resistance $[35,36]$. These considerations might also explain the cases of false positivity observed in our study: in all probability, these cases were characterized by partial and/or transient obstruction that caused only a temporary increase in the intraluminal pressure (and consequently of the RI as well), which was not sufficient to produce permanent dilation.

Some authors have found that the RI increase associated with acute urinary tract obstruction is time-dependent $[29,36]$. Opdenakker [29], for example, showed that the sensitivity of the RI decreases substantially $48 \mathrm{~h}$ after symptom onset. Platt [30] found that in patients whose obstruction had been present for $12 \mathrm{~h}$, the RI is not significantly higher than that observed in the presence of more recent obstruction. On the other hand, de Toledo [36] reported that the RI was significantly higher in patients whose renal colic had lasted at least $24 \mathrm{~h}$. These differences may be related to the duration of the obstruction and the clinical course. We found that in all patients who developed hydronephrosis, the rise in RI occurred before the onset of dilation (at least 6-12 $\mathrm{h}$ in $93 \%$ of the cases).

In accordance with the findings of Shokeir [31] and other authors, we found no significant correlation between the RI and the level of ureteral obstruction, whereas de Toledo [36] reported that proximal obstructions were associated with higher Rls than distal obstructions.

Other authors have observed a relation between the RI and the magnitude of dilation [31,35]. In our cohort, the RI exhibited no significant correlation with the degree of dilation or with the duration of the colic. 

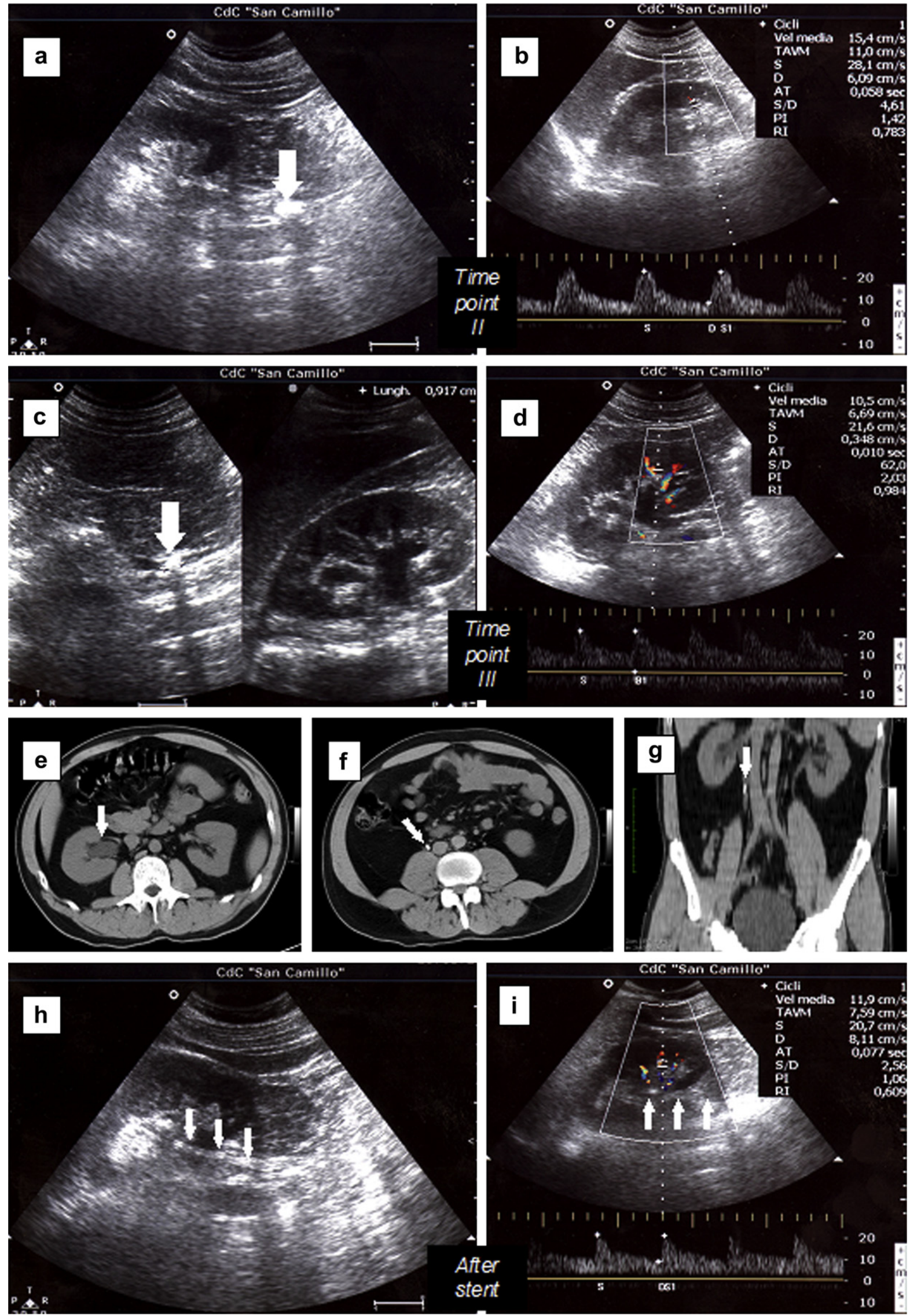

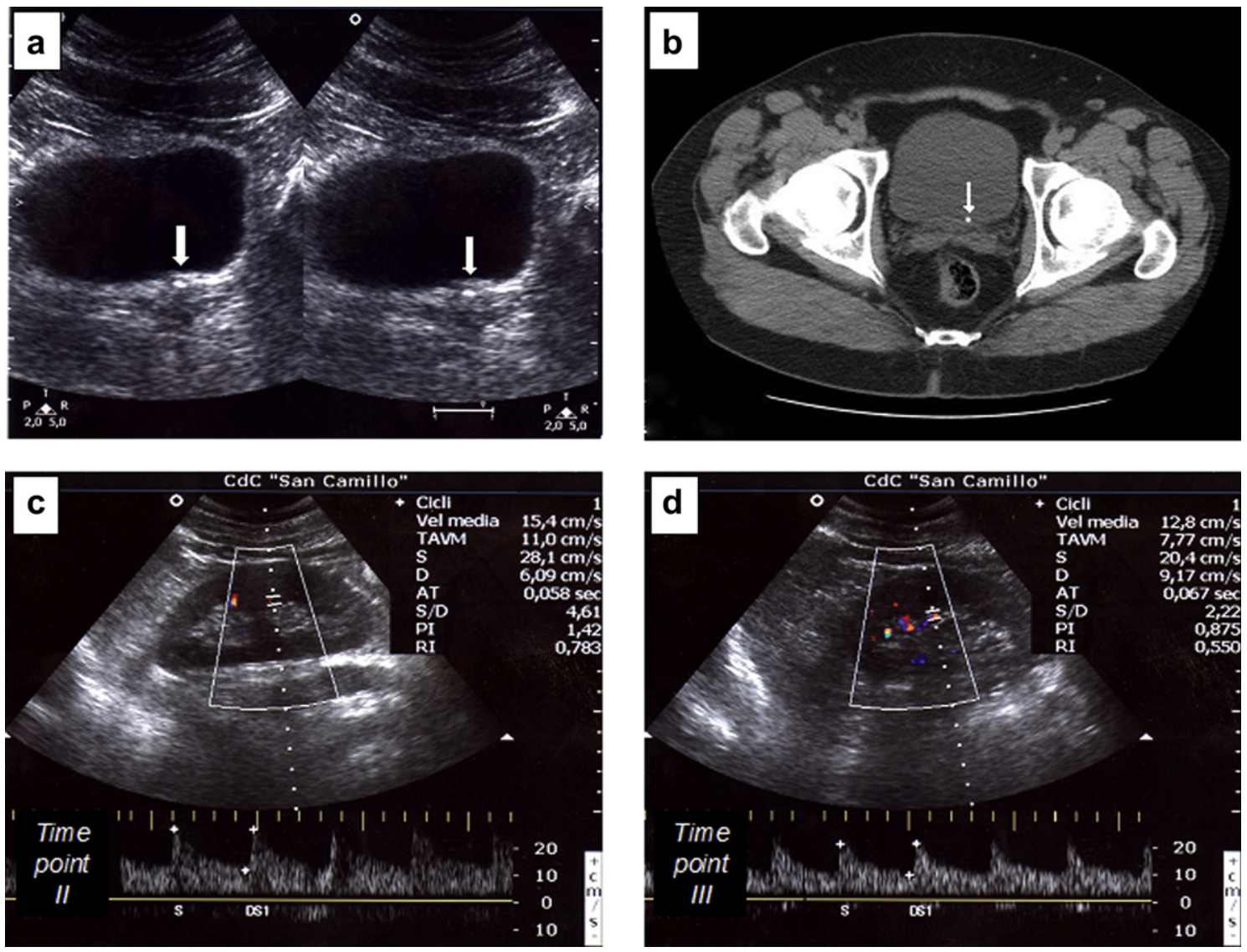

Figure 2 Example 2: Male patient admitted for left renal colic. Panels a and b: At time point (tp) I, sonography revealed a calculus at the level of the distal ureter, near the bladder (white arrow in panel a). This finding was later ( $48 \mathrm{~h}$ after admission) confirmed by urinary tract CT without contrast enhancement. Panel c: At tpll, sonography shows no evidence of hydronephrosis, but CDUS reveals $\mathrm{mRI}+$. Panel $\mathrm{d}$ : At tpIII, there is still no evidence of dilation on sonography. CDUS shows normalization of the RI even though the calculus has not been expelled. (It was expelled spontaneously one week later.)

\section{Conclusions}

CDUS with measurement of the RI is a simple, noninvasive method that furnishes acceptably precise information on the evolution of obstructive urinary tract lesions in patients with unilateral RC. In our study, this method effectively predicted the onset of acute dilatation with levels of sensitivity, specificity, accuracy, and diagnostic efficiency that were superior to those of sonography. Routine use of CDUS in the ED should be a useful supplement to ultrasonography, especially when there are contraindications for methods that involve radiation exposure (pregnancy, allergies, renal failure, etc.) or intravenous administration of iodinated contrast material (urography, CT).

\section{Conflict of interest}

The authors have no conflict of interest to disclose.

\section{Appendix A. Supplementary data}

Supplementary data related to this article can be found at http://dx.doi.org/10.1016/j.jus.2012.10.003.

Figure 1 Example 1: Male patient admitted for right renal colic. Panels a and b: At time point (tP) II, sonography revealed a calculus in the proximal ureter (white arrow in panel a) with no signs of hydronephrosis. At the same tp, CDUS showed mRI+. Panels $\mathrm{c}$ and $\mathrm{d}$ : At the next time point (tpllI), sonography confirmed the presence of the ureteral calculus (white arrow in panel $\mathrm{c}$ ) and revealed grade III hydronephrosis; CDUS confirmed $\mathrm{mRI}+$. Panels e, $\mathrm{f}$, and g: Forty-eight hours after admission, CT of the urinary apparatus without IV contrast enhancement confirmed both the grade III hydronephrosis (white arrow in panel a) and the ureteral calculosis (white arrow in panels $f$ and $g$ ). Panels $h$ and $i$ : A ureteral stent was inserted (three white arrows), and the postprocedural sonogram shows resolution of the dilation, whereas CDUS reveals normalization of the RI. 


\section{References}

[1] Esquena S, Millán Rodríguez F, Sánchez-Martín FM, Rousaud Barón F, Marchant F, Villavicencio Mavrich H. Renal colic: revision of literature and scientific evidence. Actas Urol Esp 2006;30:268-80.

[2] Teichman JM. Clinical practice. Acute renal colic from ureteral calculus. N Engl J Med 2004;350:684-93.

[3] Sterett SP, Moore NW, Nakada SY. Emergency room follow up trends in urolithiasis: single-center report. Urology 2009;73: 1195-7.

[4] Thomas A, Andrianne R. Excruciating flank pain: "acute renal colic". Rev Med Liege 2004;59:215-20.

[5] Fauci AS, Braunwald E, Isselbacher KJ, Wilson JD, Martin JB, Kasper DL, et al. Harrison's principles of internal medicine. 14th ed. New York, NY: McGraw-Hill Book Co; 1998.

[6] Smith RC, Verga M, Dalrymple N, McCarthy S, Rosenfield AT. Acute ureteral obstruction: value of secondary signs of helical unenhanced CT. AJR Am J Roentgenol 1996;167:1109-13.

[7] Shokeir AA, Abdulmaaboud M. Resistive index in renal colic: a prospective study. BJU Int 1999;83:378-82.

[8] Kartal M, Eray O, Erdogru T, Yilmaz S. Prospective validation of a current algorithm including bedside US performed by emergency physicians for patients with acute flank pain suspected for renal colic. Emerg Med J 2006;23:341-4.

[9] Pérez JA, Palmes Mde L, Ferrer JF, Urdangarain OO, Nuñez AB. Renal colic at emergency departments. Epidemiologic, diagnostic and etiopathogenic study. Arch Esp Urol 2010;63: $173-87$.

[10] Sayani R, Ali M, Shazlee K, Hamid RS, Hamid K. Functional evaluation of the urinary tract by duplex Doppler ultrasonography in patients with acute renal colic. Int $\mathrm{J}$ Nephrol Renovasc Dis 2012;5:15-21.

[11] Gettman MT, Segura JW. Updating traditional thoughts and concepts in urolithiasis. J Urol 2006;175:1602-3.

[12] Svedström E, Alanen A, Nurmi M. Radiologic diagnosis of renal colic: the role of plain films, excretory urography and sonography. Eur J Radiol 1990;11:180-3.

[13] Mutgi A, Williams JW, Nettleman M. Renal colic. Utility of the plain abdominal roentgenogram. Arch Intern Med 1991;151: 1589-92.

[14] Roth CS, Bowyer BA, Berquist TH. Utility of the plain abdominal radiograph for diagnosing ureteral calculi. Ann Emerg Med 1985;14:311-5.

[15] Tiselius HG, Ackermann D, Alken P, Buck C, Conort P, Gallucci M, et al. Guidelines on urolithiasis. Eur Urol 2001;40: 362-71.

[16] English PJ, Hungin AP, Marsden SNE. Managing acute renal colic across the primary-secondary care interface: a pathway of care based on evidence and consensus. BMJ 2003;325: $1408-12$.

[17] Elton TJ, Roth CS, Berquist TH, Silverstein MD. A clinical prediction rule for the diagnosis of ureteral calculi in emergency department. J Gen Intern Med 1993;8:57-62.

[18] Eray O, Cubuk MS, Oktay C, Yilmaz S, Cete Y, Ersoy FF. The efficacy of urinalysis, plain films, and spiral CT in ED patients with suspected renal colic. Am J Emerg Med 2003;21:152-4.

[19] Greenwell TJ, Woodhams S, Denton ER, MacKenzie A, Rankin SC, Popert R. One year's clinical experience with unenhanced spiral computed tomography for the assessment of acute loin pain suggestive of renal colic. BJU Int 2000;85: 632-6.

[20] Kirpalani A, Khalili K, Lee S, Haider MA. Renal colic: comparison of use and outcomes of unenhanced helical CT for emergency investigation in 1998 and 2002. Radiology 2005; 236:554-8.

[21] Ha M, MacDonald RD. Impact of CT scan in patients with first episode of suspected nephrolithiasis. J Emerg Med 2004;27: 225-31.

[22] Brenner DJ, Hall EJ. Computed tomography an increasing source of radiation exposure. N Engl J Med 2007;357:2277-84.

[23] Broder J, Bowen J, Lohr J, Babcock A, Yoon J. Cumulative CT exposures in emergency department patients evaluated for suspected renal colic. J Emerg Med 2007;33:161-8.

[24] Otal P, Irsutti M, Chabbert V, Murat C, Ducassé JL, Rousseau H, et al. Radiologic study of renal colic. J Radiol 2001;82:27-33.

[25] O'Malley ME, Soto JA, Yucel EK, Hussain S. MR urography: evaluation of a three-dimensional fast spin-echo technique in patients with hydronephrosis. AJR Am J Roentgenol 1997;168: 387-92.

[26] Regan F, Petronis J, Bohlman M, Rodriguez R, Moore R. Perirenal MR high signal - a new and sensitive indicator of acute ureteric obstruction. Clin Radiol 1997;52:445-50.

[27] Edmonds ML, Yan JW, Sedran RJ, McLeod SL, Theakston KD. The utility of renal ultrasonography in the diagnosis of renal colic in emergency department patients. CJEM 2010;12:201-6.

[28] Kavakli HS, Koktener A, Yilmaz A. Diagnostic value of renal resistive index for the assessment of renal colic. Singapore Med J 2011;52:271-3.

[29] Opdenakker L, Oyen R, Vervloessem I, Goethuys H, Baert AL, Baert LV, et al. Acute obstruction of the renal collecting system: the intrarenal resistive index is a useful yet time-dependent parameter for diagnosis. Eur Radiol 1998;8:1429-32.

[30] Platt JF, Rubin JM, Ellis JH. Acute renal obstruction: evaluation with intrarenal duplex Doppler and conventional US. Radiology 1993;186:685-8.

[31] Shokeir AA, Abdulmaaboud M. Prospective comparison of nonenhanced helical computerized tomography and Doppler ultrasonography for the diagnosis of renal colic. J Urol 2001; 165:1082-4.

[32] Rawashdeh YF, Djurhuus JC, Mortensen J, Hørlyck A, Frokiaer $\mathrm{J}$. The intrarenal resistive index as a pathophysiological marker of obstructive uropathy. J Urol 2001;165: 1397-404.

[33] Sauvain JL, Pierrat V, Chambers R, Bui Xuan P, Palascak P, Boursheid $D$, et al. Echography and pulsed Doppler of the arteries of the renal parenchyma in obstructive syndromes and dilatation of the excretory cavities of the kidney. J Radiol 1989;70:389-98.

[34] Granata A, Andrulli S, Bigi MQ, Pozzoni P, Fiorini F, Logias F, et al. Predictive role of duplex Doppler ultrasonography in the diagnosis of acute renal obstruction in patients with unilateral renal colic. Clin Nephrol 2009;71:680-6.

[35] Haroun A. Duplex Doppler sonography in patients with acute renal colic: prospective study and literature review. Int Urol Nephrol 2003;35:135-40.

[36] de Toledo LS, Martinez-Berganza Asensio T, Cozcolluela Cabrejas R, de Gregorio Ariza MA, Pardina Cortina P, Ripa Saldias L. Doppler-duplex ultrasound in renal colic. Eur J Radiol 1996;23:143-8. 